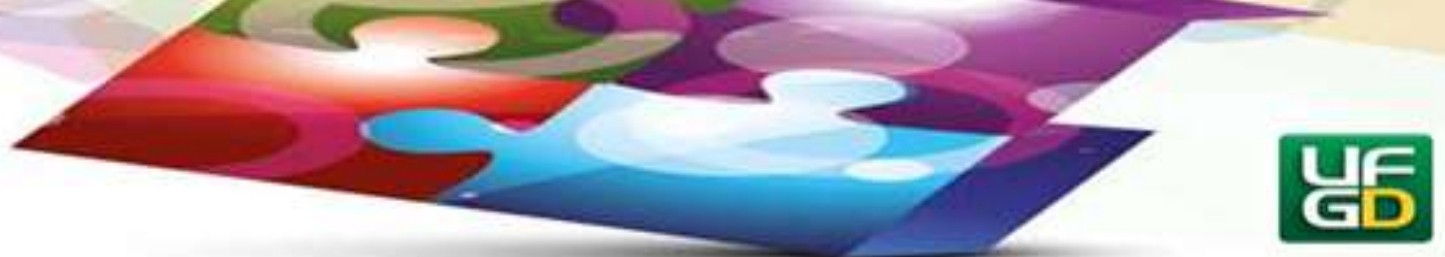

\title{
A HISTÓRIA DA EDUCAÇÃO FÍSICA ESCOLAR NO BRASIL: LEIS E DECRETOS NORTEADORES
}

\author{
LA HISTORIA DE LA EDUCACIÓN FÍSICA ESCOLAR EN BRASIL: LEYES \\ RECTORES Y DECRETO
}

Maicon Luiz MOMMAD ${ }^{1}$

\begin{abstract}
Resumo: A Educação Física Escolar no Brasil é fruto de uma construção de políticas públicas educacionais, as quais veem sendo materializadas por Leis, Decretos e instrumentos legislativos que definem seus objetivos, metas, funções e responsabilidades de todos os entes envolvidos. O presente artigo se desenvolveu por pesquisas bibliográficas e documentais, focadas em documentos oficiais, como, leis, decretos, portarias e outros documentos publicados pelo Governo Federal Brasileiro, com recorte histórico de 1937 a 2003, os quais se justificam os períodos da $1^{\circ}$ Constituição Federal de 1937 a Lei de Diretrizes e Bases da Educação de 1996 e suas portarias complementares. O objetivo da pesquisa é demonstrar o desenvolvimento histórico das políticas púbicas educacionais no campo de educação física escolar, focando principalmente no período em que a disciplina adquire status de componente curricular obrigatório na educação básica.
\end{abstract}

Palavras-chave: Educação Física Escolar. Legislação Educacional. História da Educação. Física.

Resumen: La Educación Física Escolar en Brasil es el resultado de la construcción de políticas públicas educativas, las cuales se han materializado en Leyes, Decretos e instrumentos legislativos que definen sus objetivos, metas, funciones y responsabilidades de todas las entidades involucradas. Este artículo fue desarrollado a través de una investigación bibliográfica y documental, enfocada en documentos oficiales, tales como leyes, decretos, ordenanzas y otros documentos publicados por el Gobierno Federal de Brasil, con un perfil histórico de 1937 a 2003, que justifican los períodos de la I Constitución Federal. de 1937 la Ley de Lineamientos y Bases de Educación de 1996 y sus ordenanzas complementarias. El objetivo de la investigación es evidenciar el desarrollo histórico de las políticas educativas públicas en el campo de la educación física escolar, enfocándose principalmente en el período en el que la asignatura adquiere la condición de componente curricular obligatorio en la educación básica.

Palabras-clave: Educación Física Escolar. Legislación educativa. Historia de la educación. Físico.

\section{Introdução}

\footnotetext{
${ }^{1}$ Discente do PPGEDU/UFMS. E-mail: mlmommad@ hotmail.com
} 


\section{MORIZONTES - REVISTA DE EDUCAÇÃO}

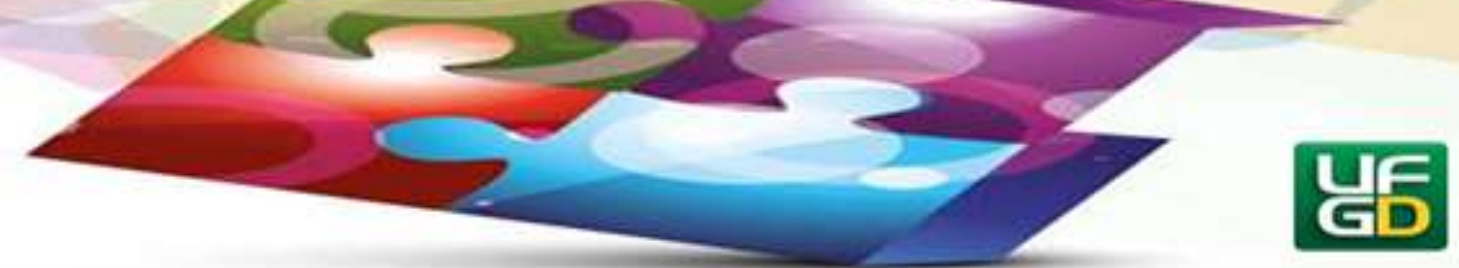

Para Thompson (1981), compreender um processo histórico é procurar, por meio das evidências históricas, apreender como os sujeitos agem e pensam dentro de determinadas condições. Para esse autor a história é concebida como processo da vida real dos homens e das relações que estabelecem entre si, entre si e a natureza, por meio do trabalho. A totalidade implica em estabelecer relação das partes como um todo estruturado.

Para melhor entendermos os impactos das legislações existentes para a disciplina de Educação Física Escolar no Brasil, é importante a compreensão de que a Educação Brasileira é regida por um Sistema Educacional, o qual sistematiza e organiza a distribuição hierárquica da responsabilidade de cada ente federativo (Governo Federal, Governo Estadual e Governo Municipal). Sistematização esta que é determinada por meio de legislações, que atribuem a esta organização hierárquica, deveres e direitos.

A pesquisa busca apresentar e compreender cada momento histórico o qual a educação física escolar foi citada em documentos oficias, e de forma bem objetiva contextualizar o seu papel no sistema educacional brasileiro, mas especificamente no contexto do currículo escolar da educação básica.

Ao detalharmos individualmente cada período, nos aproximamos de uma compreensão mais próxima da totalidade, buscando assim compreender o processo evolutivo da política educacional brasileira, especificamente da disciplina educação física escolar.

A fim de alcançarmos uma compreensão deste sistema educacional e sua trajetória histórica, realizar-se-á uma pesquisa bibliográfica e documental de toda legislação brasileira que se refira à educação física no âmbito escolar, partindo de analises da Constituição Federal de 1937, ao Decreto-Lei $n^{\circ} 10.793$ de 2003, documentos que apresentam em seu corpo, referencia a educação física escolar na educação básica brasileira.

Destaca-se também que serão realizadas abordagens referentes as políticas sociais e econômicas de cada período histórico analisado, com vista a contribuir para melhor compreensão das medidas adotadas no período histórico referido de cada documento analisado, mas não sendo o objetivo da pesquisa analisar as políticas de governo. Mas faz-se necessária as citações do contexto para compreender a construção de tais documentos, segundo Rodriguez (2004, p.26): 


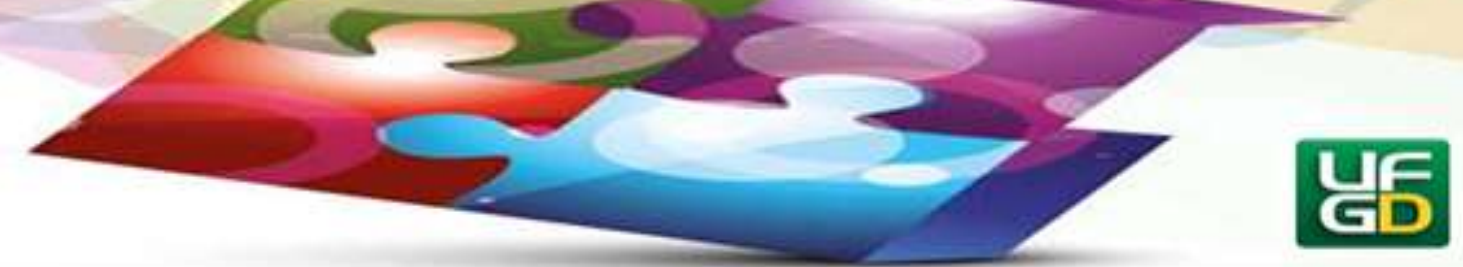

[...] são elaborados por pessoas de épocas e grupos sociais diferentes, e a produção destas pessoas é permeada de elementos determinantes, seja pelo cargo que ocupa ou pela própria inserção social. Em tal sentido, o historiador deve ficar muito alerta e não pode esquecer o contexto da produção dos textos (RODRIGUEZ, 2004, p. 26).

Para Thompson (1998), embora os eventos sociais e culturais sejam causalmente condicionados por eventos econômicos, possuem autonomia.

Assim, os fenômenos sociais e culturais não podem ser analisados apenas como reflexo imediato da vida econômica. A partir das evidências, é preciso investigar suas particularidades e, ao mesmo tempo, como se expressam em condições materiais constituídas historicamente. Assim, os próprios valores de uma sociedade são percebidos entrelaçados com a vida material e como resultado das experiências humanas, segundo Thompson (1981, p.194):

Os valores não são "pensados", nem "chamados"; são vividos, e surgem dentro do mesmo vínculo com a vida material e as relações materiais em que surgem nossas ideias. São as normas, regras, expectativas etc. necessárias e aprendidas (e "aprendidas" no sentimento) no "habitus" de viver; e aprendidas, em primeiro lugar, na família, no trabalho e na comunidade imediata. Sem esse aprendizado a vida social não poderia ser mantida e toda produção cessaria (THOMPSON, 1981, p. 194).

Os documentos acima citados serão analisados no contexto da proposição de políticas educacionais para educação física escolar no Brasil, e para que possamos entender como se deu o seu inicio. Par uma melhor organização didática partiremos da analise da Constituição Federal de 1937, sendo a primeira legislação, que apresenta em seu texto, referencia à Educação Física Escolar.

\section{A Constituição Federal de 1937}

Ao analisarmos os documentos históricos que citam a educação física oficialmente, como prática educativa obrigatória no contexto escolar, nos deparamos com a Constituição de 1937. Primeiro documento que apresenta referência explicita a inclusão da Educação Física como pratica educativa obrigatória, mas ainda não a tratando como disciplina curricular.

Importante compreender que na década de 1930 o país passa por um processo de industrialização e urbanização e estabelecimento do Estado Novo, este contexto histórico fortalece a necessidade de formação de trabalhadores com mais capacidade produtiva, portanto se faz necessária uma melhor saúde física. 


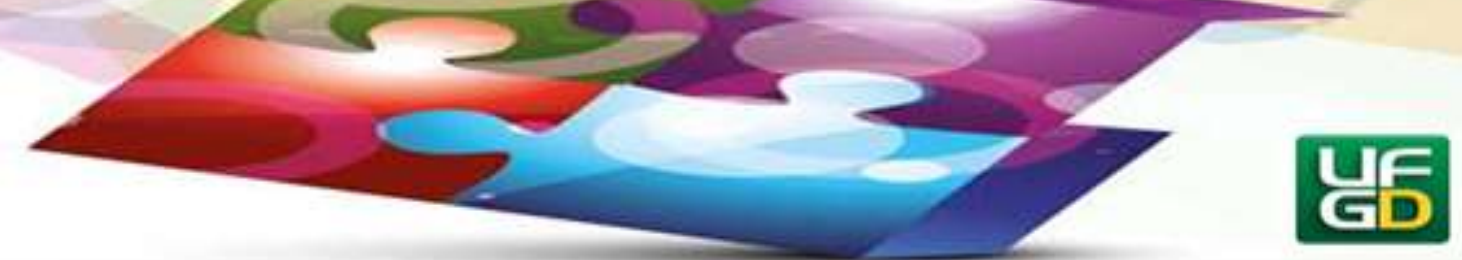

Então neste período se estabelece uma Educação Física em uma perspectiva higienista. Que através de hábitos de higiene e por meios de exercícios físicos, melhorar a qualidade de vida a população.

Segundo Castellani Filho (2004), analisando o que dizia a constituição brasileira de 1937, na qual sua finalidade era promover a disciplina e a moral e o adestramento físico de maneira a preparar o aluno para o cumprimento dos seus deveres para com a economia e a defesa da nação.

Fica evidente a intenção não somente de uma educação física que preparasse os corpos como força de trabalho, mas também para uma militarização, tendo em vista o período histórico de guerras presentes no cenário mundial.

Para Castellani Filho (1994) a Educação Física nesse contexto, tinha suas delimitações notoriamente influenciadas pelos militares e pelos médicos que "auto proclamavam-se a mais competente das categorias profissionais para redefinir os padrões de conduta física, moral e intelectual da nova família brasileira” (CASTELLANI FILHO, 1994, p.39).

Apesar de todo empirismo que permeava a educação física escolar neste momento histórico, houve ganho com a introdução da educação física como prática pedagógica obrigatória, pois a mesma começa a ser entendida como prática importante no contexto escolar.

Destaca-se que a Constituição Federal de 1946, não trás nenhuma menção a Educação Física Escolar no corpo de seu texto, ficando este período referenciado sob o texto da constituição de 1937.

\section{LDB - Lei n4.024/1961}

A primeira Lei de Diretrizes e Bases da Educação (LDB) apresenta em seu texto a estruturação da educação escolar em dois níveis, Primário (quatro anos) e Ginásio (quatro anos).

No que se refere Educação Física, fica determinado em seu Art. 22 que será obrigatória a prática da educação física nos cursos primário e médio, até a idade de 18 anos. 


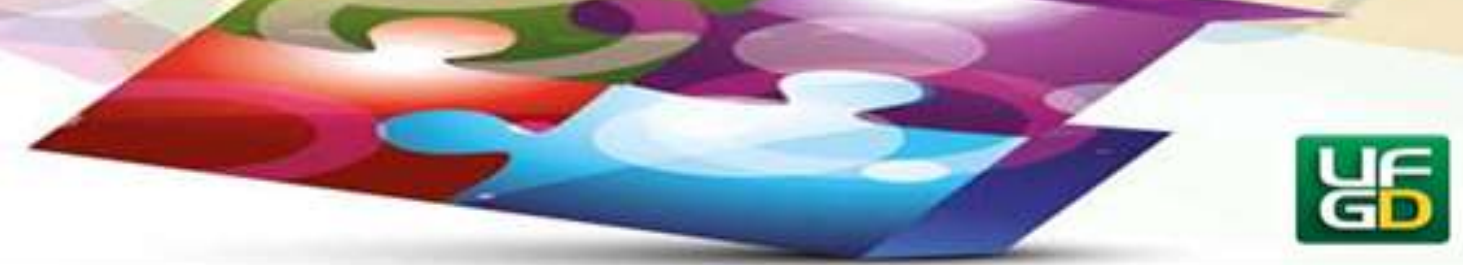

Segundo Castellani Filho (1998), a obrigatoriedade da sua prática até os 18 anos se justificava pela compreensão de que era essa a idade na qual se dava o término do processo de instrução escolar e o ingresso no mercado de trabalho.

Fica também explicitado neste período o processo de esportivização da Educação Física escolar, evidenciado através do Método Desportivo Generalizado, na tentativa de incorporar o esporte, adequando-o aos objetivos e práticas pedagógicas.

Esse período destaca-se por anteceder o Golpe Cívico-militar, ficando evidente que o contexto social da época, enfatiza a educação como instrumento de formação para o mercado de trabalho, evidenciando assim a forte corrente capitalista vigente na sociedade brasileira e suas influencias nas políticas educacionais deste período histórico.

\section{Decreto Lei n⿳5十8.130/1966}

Já no período da Ditadura Civil-Militar foi publicado o Decreto Lei no 58. 130/1966 que regulamentava o art. 22 da Lei $\mathrm{n}^{\circ} 4.024$, de 20 de dezembro de 1961, que fixava as Diretrizes e Bases da Educação Nacional.

O Decreto Lei, diz que:

Art. $1^{\circ}$ A Educação Física, prática educativa tornada obrigatória pelo art. 22 da Lei de Diretrizes e Bases, para os alunos dos cursos primários e médio até a idade de 18 anos, tem por objetivo aproveitar e dirigir as forças do indivíduo - físicas, morais, intelectuais e sociais - de maneira a utilizá-las na sua totalidade, e neutralizar, na medida do possível, as condições negativas do educando.

Castellani Filho (1998) explica o papel da Educação Física durante a ditadura militar em colaborar, através de seu caráter lúdico-esportivo, com o esvaziamento de qualquer tentativa de articulação política que pudessem colocar em risco a consecução do projeto de sociedade em construção.

Além do caráter disciplinador, a partir do Golpe Cívico-militar de 1964, a Educação Física, passa a sofrer influencias da tendência tecnicista, visto como uma maneira de se formar mão de obra qualificada.

Segundo Saviani (1976), a alternativa era ajustar a ideologia política ao modelo econômico ou vice-versa. O Golpe Cívico-militar de 1964 resolveu a contradição de forma a ajustar a ideologia política aos interesses do modelo econômico. 


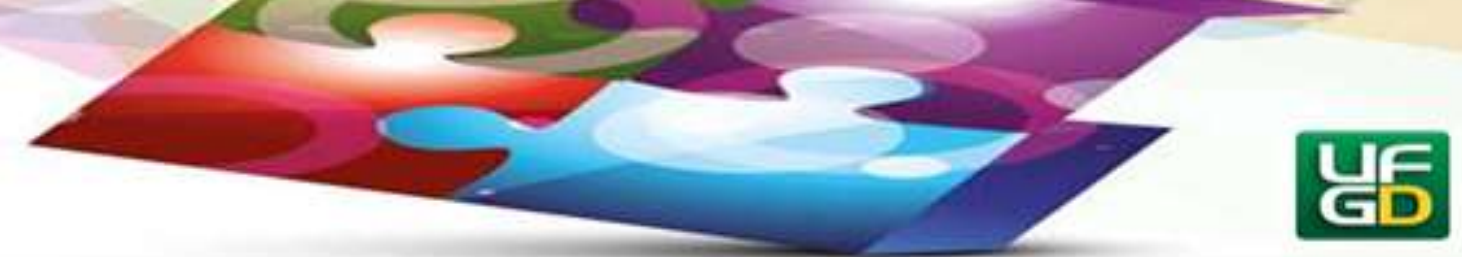

Como aponta a literatura, a partir de 1964, a legislação educacional brasileira, é pensada em consonância com os interesses econômicos deste período, onde a economia nacional se volta para abertura de capital e empresas estrangeiras, atendendo o modelo liberal da época.

A ideia central da política educacional no período da Ditadura Civil-militar é propor o controle ideológico e cultural, cerceando a ideia da educação como agente emancipador, mas sim um agente alienador, assim como nós explica Ianni (1963, p.264):

Para os que se encontram prêsos econômica, política e ideològicamente ao ensino
privado, é fundamental a manutenção dêsse tipo de alienação, contra a qual lutam
aqueles que defendem a escola pública gratuita e aberta a todos. Êles estão
preocupados com a preservação de instituições educacionais que formem cidadãos
insuficientemente preparados para a plena compreensão de sua posição na
sociedade, isto é, na história. Indivíduos parcialmente elaborados, ou deformados, na
acepção política do termo; mas submissos, dóceis a todo tipo de expoliação (IANNI,
1963, p. 264).

Este processo de controle ideológico do sistema educacional apresenta-se em outros documentos deste período histórico, demonstrando de forma clara os objetivos da política proposta pelo regime ditatorial brasileiro. A seguir apresentaremos uma lei que de forma complementar a esta, reforça a ideia da educação física como instrumento disciplinador e alienador.

\section{Lei $n^{0}$ 5.692/1971}

A Lei n 5.692 de 1971, novamente reproduz as ideias do governo vigente, sendo a Educação Física reforçada em seu caráter instrumental, considerada uma atividade prática, voltada ao desempenho técnico e físico do aluno.

Este é um período em que o Brasil passa por um duro regime ditatorial, e sendo a Educação Física uma pratica física de grande poder disciplinador, os militares no governo investem na educação física, como um instrumento para reforçar as questões nacionalistas, de segurança nacional, tanto na formação de jovens fortes e saudáveis, usados no exercito, como na desmobilização de forças políticas oposicionistas.

Ressalta-se que neste momento histórico, o Brasil passa também por um período econômico de crise, e novamente a educação física é utilizada como instrumento, aqui a ideia 


\section{HORIZONTES - REVISTA DE EDUCAÇÃO}

é a melhoria da força de trabalho, formar trabalhadores mais saudáveis e fortes, para ajudar no projeto nacional denominado "milagre econômico brasileiro".

Fica evidente que, as questões pedagógicas, não são levadas em consideração, tendo em vista que o período histórico e o projeto de sociedade impostos, não se interessam por qualificar a Educação Física no campo pedagógico e sim no campo físico/biológico.

\section{Decreto-Lei no 69.450/1971}

Segundo Martins (2012), a novidade apresentada neste decreto é a ampliação da obrigatoriedade da disciplina Educação Física a todos os níveis de escolarização, trás também as orientações de como ela deverá acontecer no ensino primário e ensino médio.

Cita-se aqui o artigo segundo do decreto que trata sobre a obrigatoriedade a todos os níveis de escolarização: Art. $\mathbf{2}^{\mathbf{0}}$. A educação física, desportiva e recreativa integrará, como atividade escolar regular, o currículo dos cursos de todos os graus de qualquer sistema de ensino (BRASIL, 1971).

Outro ponto relevante, e quanto à diferenciação dos conteúdos e objetivos que a partir do decreto se dão aos níveis do ensino primário e médio, onde o ensino primário deverá seguir o caráter recreativo conforme descrito abaixo no artigo $3^{\circ}$ parágrafo I:

I - No ensino primário, por atividades físicas de caráter recreativo, de preferência as que favoreçam a consolidação de hábitos higiênicos, o desenvolvimento corporal e mental harmônico, a melhoria da aptidão física, o despertar do espírito comunitário da criatividade, do sendo moral e cívico, além de outras que concorram para completar a formação integral da personalidade (BRASIL, 1971).

Já o ensino médio passa a ter outra conotação, pois além dos objetivos elencados na lei, havia os objetivos governamentais intrínsecos, que neste período histórico era de controle social. Assim a educação física no nível de ensino médio, toma um caráter esportivo, conforme o artigo $3^{\circ}$ parágrafo II:

\footnotetext{
II - No ensino médio, por atividades que contribuam para o aprimoramento e aproveitamento integrado de todas as potencialidades físicas, morais e psíquicas do indivíduo, possibilitando-lhe pelo emprego útil do tempo de lazer, uma perfeita sociabilidade a conservação da saúde, o fortalecimento da vontade, o estímulo às tendências de liderança e implantação de hábitos sadios [...] § $2^{\circ}$ A partir da quinta série de escolarização, deverá ser incluída na programação de atividades a iniciação desportiva (BRASIL, 1971)
} 


\section{MORIZONTES - REVISTA DE EDUCAÇÃO}

Neste momento histórico, a educação física é norteada por um "modelo piramidal", que seu objetivo era melhoria da aptidão física da população urbana, e o fomento do desporto de massa, tornando-se um desporto de elite, com a seleção de indivíduos aptos para competir dentro e fora do país.

Mas como em leis e decretos citados anteriormente, a Educação Física, fica longe de um caráter pedagógico, continuando como seu principal objetivo o preparo do corpo para o trabalho, continua o corpo sendo abordado de forma física e biológica.

Segundo Martins (2012), outro ponto de destaque é a disciplina escolar Educação Física, que continua sendo apenas um componente extracurricular, sem compromisso formativo, uma disciplina acrítica e de práticas corporais.

Importante salientar que é neste período que surgem as correntes criticas da educação física brasileira, correntes essas que serão importantes para o avanço das pesquisas e discussões no campo teórico, e que darão subsídios para que a educação física seja vista e repensada como conteúdo pedagógico importante no ambiente escolar. Assim como será tratada na próxima lei a ser discutida, a LDB de 1996, que trás avanços importantes para área da educação física escolar.

\section{LDB - Lei n 9.394/1996}

A partir da promulgação da Lei de Diretrizes e Bases da Educação de 1996, a Educação Física Escolar assume um caráter pedagógico, passa a ser considerada um componente curricular da educação básica, fazendo-se presente na proposta pedagógica da escola, assim como determinar o Art.26, $\S 3^{\circ}$ :

$\S 3^{\circ}$. A Educação Física, integrada à proposta pedagógica da escola, é componente curricular da educação básica, ajustando-se as faixas etárias e às condições da população escolar, sendo facultativa nos cursos noturnos (BRASIL, 1996)

A LDB de 1996 avança em garantir a Educação Física nos níveis de Educação Básica, como afirma Castellani Filho (1998, p.22):

Retira-se, com essa redação, a camisa de força que a aprisionava nos limites próprios ao famigerado eixo paradigmático da aptidão física, à medida que a vinculava tão somente à busca do desenvolvimento fisco dos alunos [...] (CASTELLANI FILHO, 1998, P.22) 


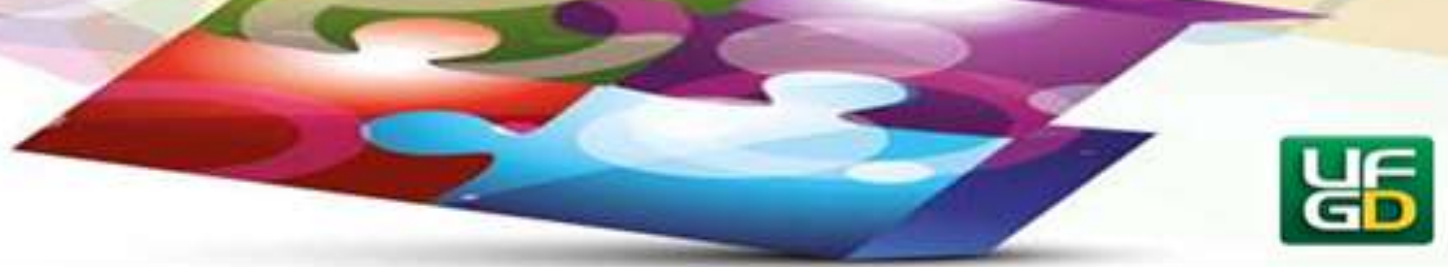

Contudo os avanços da Educação Física na Educação Básica, o Ensino Superior fica excluído desta obrigação, o que causa segundo Castellani Filho (1998) diversos debates sobre o referido assunto, sendo o mesmo encaminhado a Câmara de Educação Superior do Conselho Nacional de Educação para apreciação.

Como relação à obrigatoriedade ou não da Educação Física no Ensino Superior, Castellani Filho (1998) explica que a Câmara de Educação Superior do Conselho Nacional de Educação decide que, "cabem às instituições de Ensino Superior decidir sobre a oferta ou não de Educação Física nos seus cursos de graduação".

Destaca-se que após a publicação da Lei de Diretrizes e Bases da Educação de 1996, a mesma ainda receberá algumas atualizações, através de decretos-lei, os quais trarão pequenas alterações ao texto original, mas que em determinados momentos terão grande relevância para o contexto educacional, assim como os decretos que discutiremos a seguir.

\section{Decreto-Lei nº.328/2001}

Este decreto vem em complementação a LDB de 1996, onde o mesmo introduz no texto da LDB/96 Art. 26, $\S 3^{\circ}$ a palavra, "obrigatório", após a expressão componente curricular, ficando o novo texto com a seguinte escrita:

$\S 3^{\circ}$. A Educação Física, integrada à proposta pedagógica da escola, é componente curricular obrigatório da educação básica, ajustando-se as faixas etárias e às condições da população escolar, sendo facultativa nos cursos noturnos (BRASIL, 2001).

A introdução da palavra obrigatório, no texto da LDB, que se refere à Educação Física, tem grande relevância quando se trata de garantia de direito da obrigatoriedade da política publica educacional, pois assim garante-se que a disciplina de Educação Física, além de ganhar a notoriedade de componente curricular, seja obrigatória nas grades curriculares da educação básica.

\section{Decreto-Lei $N^{\circ} 10.793 / 2003$}

Este outro decreto também trás vistas ao texto original da LDB/96, sendo a Educação Física ser obrigatória para todos os turnos de estudos e facultativa ao aluno que trabalha sei 
horas ou mais, mas devendo ser oferecida de como optativa no período noturno, assim como trás o novo texto:

$\S 3^{\circ}$. A educação física, integrada à proposta pedagógica da escola, é componente curricular obrigatório da educação básica, sendo sua prática facultativa ao aluno: I que cumpra jornada de trabalho igual ou superior a seis horas; II - maior de trinta anos de idade; III - que estiver prestando serviço militar inicial ou que, em situação similar, estiver obrigado à prática da educação física; IV - amparado pelo DecretoLei ${ }^{\circ} 1.044$ de 21 de outubro de 1969; V - (VETADO); VI - que tenha prole (BRASIL, 2003).

\section{Considerações Finais}

Como apresentado durante todo o artigo a Política Educacional Brasileira, especificamente da Educação Física Escolar no âmbito da educação básica, vem sendo construída através de leis e decretos que visam sistematizar seus objetivos, metas e responsabilidades em seus diversos níveis de escolaridade e ambitos de responsabilidade.

Fica evidente com a leitura dos dispositivos legais abordados, que nunca foi uma preocupação, tratar o aluno na sua totalidade, a preocupação com as questões pedagógicas foram sempre deixas em segundo plano, pois a educação física por anos foi utilizada como instrumento materialização de interesses políticos e governamentais de uma elite dominante.

Por um longo período, a educação física, sempre foi um instrumento de alienação corporal, com o objetivo de formar corpos saudáveis e fortes, para atender a demanda do capital, de um trabalhador saudável.

Faz-se necessário aprofundar os debates e pesquisas no campo das políticas educacionais da educação física, trazer a luz do conhecimento, seus benefícios sociais e pedagógicos, que transcendem os benefícios físicos por anos associados a ela. As leis e decretos devem contemplar todos os níveis de escolaridade, trazer mecanismos mais claros e concretos da efetivação das políticas públicas da educação física no âmbito escolar.

Contudo, somente com pesquisa e consultas aos profissionais, que atuam diretamente com a prática da educação física escolar, nossos legisladores terão subsídios para proporem leis, que terão efetiva relevância pedagógica e social, pois é preciso que estas leis estejam adequadas a cada período histórico e as particularidades regionais de nosso país. 


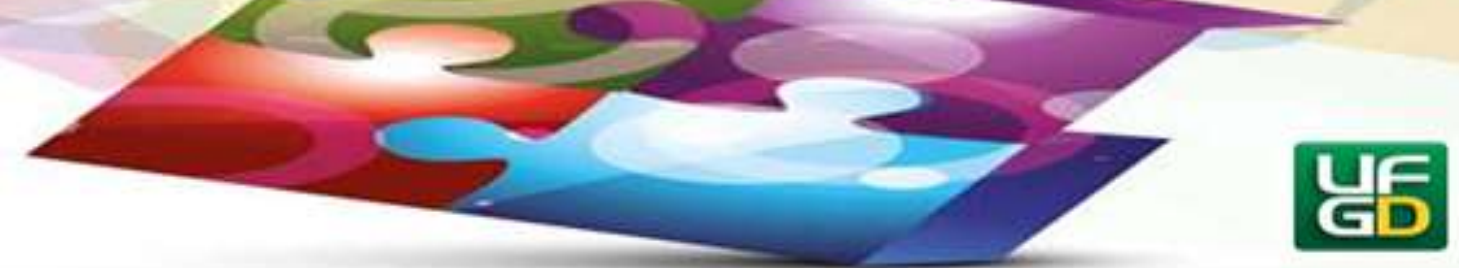

\section{Referências}

BRASIL. Lei de Diretrizes e Bases. Lei no 4.024/61 de 20 de dezembro de 1961.

$1-5 / 4 / 1966$, Página 3596.

. Decreto Lei no 58.130 de 31 de março de 1966. Diário Oficial da União - Seção

. Lei de Diretrizes e Bases. Lei $\mathbf{n}^{\mathbf{0}} \mathbf{5 . 6 9 1 / 7 1}$ de 1 de agosto de 1971.

1997. 96p.

.Parâmetros Curriculares Nacionais: Educação Física. Brasília: MEC/SEF,

Lei de Diretrizes e Bases. Lei n⿳ 9.394/96 de 20 de dezembro de 1996.

Decreto Lei $\mathbf{n}^{\circ} \mathbf{1 0 . 3 2 8}$ de 12 de dezembro de 2001. Diário Oficial da União Seção 1 - 13/12/2001, Página 1.

Decreto Lei $\mathbf{n}^{\circ} \mathbf{1 0 . 7 9 3}$ de 01 de dezembro de 2001. Diário Oficial da União Seção 1 - 2/12/2003, Página 10

CASTELLANI FILHO, Lino. Educação Física no Brasil: a história que não se conta. $4^{\mathrm{a}}$ ed. Campinas: Papirus, 1994.

Política educacional e educação física: polemicas do nosso tempo. Campinas: Autores Associados, 1998, 93p.

Educação física no Brasil: A história que não se conta. 10. ed. Campinas, SP:

Papirus, 2004. 225 p.

IANNI, O. Industrialização e desenvolvimento social no Brasil. Rio de Janeiro: Civilização Brasileira, 1963. (Retratos do Brasil, v. 19).

MARTINS, T. A; SILVA, G. M. As LDB's no Brasil: implicações na prática de ensino da Educação Física na Educação Básica. EFDesportes.com, Revista Digital. Buenos Aires, Ano 17, n¹72, Setembro de 2012. http://www.efdeportes.com/efd172/as-ldbs-no-brasileducacao-fisica.htm em 14/03/2019.

RODRIGUEZ, Margarita Victoria. A pesquisa documental e o estudo histórico de políticas educacionais. In: $O$ Guardador de Inutensílios. Cadernos de Cultura. n.7, p.17-30, maio 2004.

SAVIANI, Dermeval. Análise crítica da organização escolar brasileira através das leis 5.540/68 e 5.692/71. In: GARCIA, Walter E. Educação brasileira contemporânea: organização e funcionamento. São Paulo: McGraw- Hill, 1976. 


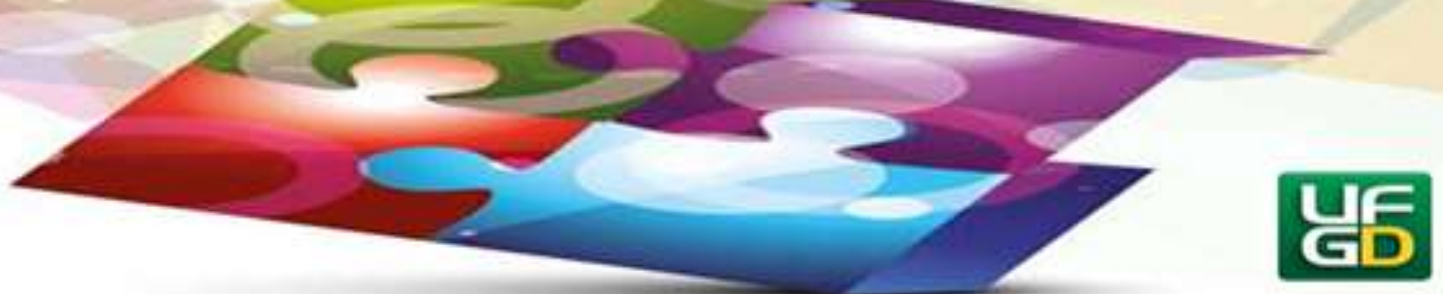

THOMPSON, E. P. A miséria da teoria ou um planetário de erros: uma crítica ao pensamento de Althusser. Rio de Janeiro: Zahar, 1981.

Enviado: $30 / 06 / 2020$

Aceito: $31 / 08 / 2020$ 